\title{
Fatty acid composition from the marine red algae Pterocladiella capillacea (S. G. Gmelin) Santelices \& Hommersand 1997 and Osmundaria obtusiloba (C. Agardh) R. E. Norris 1991 and its antioxidant activity
}

\author{
DANIEL B. DE ALENCAR ${ }^{1}$, JAÉCIO C. DINIZ ${ }^{2}$, SIMONE A.S. ROCHA ${ }^{2}$, KELMA M.S. \\ PIRES-CAVALCANTE ${ }^{1}$, REBECA L. DE LIMA ${ }^{1}$, KAROLINA C. DE SOUSA ${ }^{1}$, JEFFERSON \\ O. FREITAS ${ }^{1}$, RAYSSA M. BEZERRA ${ }^{1}$, BÁRBARA M. BARACHO ${ }^{1}$, ALEXANDRE H. \\ SAMPAIO ${ }^{1}$, FRANCISCO A. VIANA $^{2}$ and SILVANA SAKER-SAMPAIO ${ }^{1}$ \\ ${ }^{1}$ Departamento de Engenharia de Pesca, Laboratório de Produtos Naturais Marinhos, Universidade Federal \\ do Ceará, Campus do Pici, Av. Mister Hull, s/n, Caixa Postal 6043, 60455-970 Fortaleza, CE, Brazil \\ ${ }^{2}$ Departamento de Química, Laboratório de Cromatografia, Universidade do Estado do Rio Grande do Norte, \\ Campus Universitário Central, Setor III, Rua Prof. Antônio Campos, s/n, 59633-010 Mossoró, RN, Brazil
}

Manuscript received on May 23, 2016; accepted for publication on August 15, 2016

\begin{abstract}
This study evaluated the chemical composition and antioxidant activity of fatty acids from the marine red algae Pterocladiella capillacea (S. G. Gmelin) Santelices \& Hommersand 1997 and Osmundaria obtusiloba (C. Agardh) R. E. Norris 1991. The gas chromatography mass spectrometry (GC-MS) identified nine fatty acids in the two species. The major fatty acids of $P$. capillacea and $O$. obtusiloba were palmitic acid, oleic acid, arachidonic acid and eicosapentaenoic acid. The DPPH radical scavenging capacity of fatty acids was moderate ranging from $25.90 \%$ to $29.97 \%$. Fatty acids from P. capillacea $(31.18 \%)$ had a moderate ferrous ions chelating activity (FIC), while in $O$. obtusiloba $(17.17 \%)$, was weak. The ferric reducing antioxidant power (FRAP) of fatty acids from P. capillacea and O. obtusiloba was low. As for $\beta$-carotene bleaching (BCB), P. capillacea and O. obtusiloba showed a good activity. This is the first report of the antioxidant activities of fatty acids from the marine red algae P. capillacea and O. obtusiloba.
\end{abstract}

Key words: Fatty acids, antioxidant activity, palmitic acid, Rhodophyta.

\section{INTRODUCTION}

Oxidative stress represents a considerable increase in the intracellular concentration of oxidizing species, such as reactive oxygen species (ROS), simultaneously accompanied by the loss of

Correspondence to: Daniel Barroso de Alencar

E-mail: daniellpesca@gmail.com

Silvana Saker-Sampaio

E-mail: sakersil@gmail.com antioxidant defense. This process can cause tissue damage or cell death, which occurs primarily by necrosis and apoptosis. Also, the oxidative stress plays a key role in inflammatory processes, aging and diseases such as atherosclerosis, cancer, central nervous system disorders, arthritis, diabetes, cardiovascular and neurological disorders (Parkinson's and Alzheimer's) (Boisvert et al. 2015, O’Sullivan et al. 2011, Tierney et al. 2013). 
In addition to the damage caused to cellular components, ROS can also breakdown fatty acids present in the food. This change is responsible for the development of rancid odor and flavor resulting in diminished nutritional quality and safety, due to the formation of secondary products, potentially toxic (Ngo et al. 2012, O'Sullivan et al. 2011).

Consumption of antioxidants and/or the incorporation in food products are intended to promote a protective effect against these phenomena, thus extending the food shelf life. Several synthetic antioxidants, such as butylhydroxyanisole (BHA), butylated hydroxytoluene (BHT) and tertbutylhydroquinone (TBHQ), are available on the market, being widely used in food industries. The drawback in the use of these chemical compounds lies in the fact that some toxicological studies have proved that, depending on the concentration, synthetic antioxidants can promote the development of tumor cells in rats (Huang and Wang 2004, Souza et al. 2011).

Given the toxic and carcinogenic effects caused by synthetic compounds, the search for natural antioxidants has attracted considerable attention in the last decade. Studies have examined marine organisms for being promising sources of bioactive compounds with valuable nutraceutical and pharmaceutical potential, including algae, which are among the richest sources of biologically active molecules with different properties (Dolatabadi and Kashanian 2010, Ngo et al. 2011).

Marine algae live in complex habitats and are subjected to wide fluctuations in temperature, salinity, light, nutrients, contaminants like heavy metals etc., and thus naturally forced to adapt to changing environmental conditions, producing a wide range of primary and secondary metabolites that cannot be found in other organism from terrestrial environments (Francavilla et al. 2013, Lordan et al. 2011, Rodrigues et al. 2015).

Marine algae produce many biologically active phytochemical constituents such as volatile organic compounds, carotenoids, terpenes, chlorophylls, phycobilins, polysaccharides, vitamins, steroids, phenolic compounds, alkaloids and fatty acids, making them increasingly interesting for commercial purposes (Fernandes et al. 2014, Francavilla et al. 2013, Hafting et al. 2015).

The search for new sources of bioactive compounds with potentially beneficial properties currently has a huge importance in the biomedical and pharmacological areas. These compounds have various biological activities and may act as antioxidant, antimicrobial, antiviral, antiinflammatory, antinociceptive, antitumor, anticoagulant, and anticonvulsant agents. From a nutritional perspective, in Western countries, it has seen a greater interest in adopting increasingly healthy eating habits and, in this context, algae have been treated as functional foods (Alencar et al. 2014, 2016, Fernandes et al. 2014, Holdt and Kraan 2011, Plouguerné et al. 2014).

In recent years, the lipid composition of marine algae has attracted the attention of researchers due to the high content of polyunsaturated fatty acids, mainly the $\alpha$-linolenic, octadecatetraenoic, arachidonic and eicosapentaenoic acids. This class of fatty acids was considered as essential nutritional components for humans and animals, playing an important role in preventing cardiovascular disease, osteoarthritis, diabetes and also presenting antiviral, anti-inflammatory, antitumor, antimicrobial and antioxidant activities (Kendel et al. 2015).

Henry et al. (2002) reported the antioxidant activity of 29 saturated and unsaturated fatty acids commercially available. These authors observed that most unsaturated fatty acids showed good antioxidant activity. These lipophilic constituents of marine algae may be useful in the food industry for protection against lipid peroxidation due to low polarity and ease of dissolution (Huang and Wang 2004). 
This study aimed to analyze for the first time the composition of fatty acids from lipid fraction present in the marine red algae Pterocladiella capillacea (S. G. Gmelin) Santelices \& Hommersand 1997 and Osmundaria obtusiloba (C. Agardh) R. E. Norris 1991, by GC-MS (qualitatively) and GCFID (quantitatively), and to evaluated its "in vitro" antioxidant activity.

\section{MATERIALS AND METHODS}

\section{COLLECTION AND IDENTIFICATION OF MARINE ALGAE}

Specimens of the marine red algae Pterocladiella capillacea (S. G. Gmelin) Santelices \& Hommersand 1997 were collected in March 2008, at the Pacheco Beach, Caucaia, Ceará, Brazil. Specimens of the marine red algae Osmundaria obtusiloba (C. Agardh) R. E. Norris 1991 were collected in September 2010, at the Paracuru Beach, in São Gonçalo do Amarante, Ceará, Brazil, both in low tide conditions, with the permission of the Brazilian Institute of Environment and Renewable Natural Resources (SISBIO 33913-1).

Algae collected were washed with distilled water to remove impurities and macroscopic epiphytes and then placed on absorbent paper to remove excess water and frozen at $-24^{\circ} \mathrm{C}$ until analyses.

The species were identified in the Department of Fisheries Engineering, Federal University of Ceará. The voucher specimens of $P$. capillacea and O. obtusiloba were deposited in the Prisco Bezerra Herbarium, Department of Biology of the same University, with the numbers 447310 and 56432 , respectively.

\section{LIPID EXTRACTION}

Fresh algae were dried in a circulating air oven at $40^{\circ} \mathrm{C}$ for $15 \mathrm{~h}$ and then ground. Portions of dried material of P. capillacea (134 g) and O. obtusiloba $(120 \mathrm{~g})$ were exhaustively extracted with cold hexane. The hexane extract (Hex) was concentrated in a rotary evaporator.

\section{FATTY ACID EXTRACTION}

Fatty acid extraction followed the method described by Joseph and Ackman (1992). In separate, we weighed $80.3 \mathrm{mg}$ and $50.1 \mathrm{mg}$ of hexane extracts from $P$. capillacea and O. obtusiloba, respectively. Then, there were added $6 \mathrm{~mL} 0.5 \mathrm{M} \mathrm{NaOH}$ solution in methanol; the tubes were taken to a water bath at $100^{\circ} \mathrm{C}$ for $10 \mathrm{~min}$ and then cooled to room temperature. After cooling, there were added $6 \mathrm{~mL}$ $14 \%$ boron trifluoride $\left(\mathrm{BF}_{3}\right)$ in methanol and the tubes were heated again in a water bath, at $100^{\circ} \mathrm{C}$ for $30 \mathrm{~min}$, to occur methylation of fatty acids. After cooled to room temperature, there were added 15 $\mathrm{mL}$ saturated solution of sodium chloride, stirred and then added with $6 \mathrm{~mL}$-hexane to extract the fatty acid methyl esters. The organic fraction (hexane) was analyzed for the composition and quantification of fatty acids by gas chromatography coupled to mass spectrometry (GC-MS) and gas chromatography with flame ionization detector (GC-FID).

\section{CHROMATOGRAPHIC CONDITIONS}

Gas chromatography mass spectrometry (GC-MS)

The qualitative analysis of fatty acids in the form of methyl esters was performed on GC-MS (Shimadzu GC/MS QP-2010 Ultra) with silica nonpolar capillary column Restek Rtx-5ms (30 $\mathrm{m} \times 0.25 \mathrm{~mm}$ i.d. $x$ film thickness $0.25 \mu \mathrm{m}$.) The injection volume was $1 \mu \mathrm{L}$ at a concentration of $1,000 \mu \mathrm{g} \mathrm{mL}^{-1}$ of the sample at 1:10.

Chromatographies were made by adjusting the injector temperature at $250^{\circ} \mathrm{C}$ and the detector temperature at $200^{\circ} \mathrm{C}$. The carrier gas used was helium with a flow rate of $1.4 \mathrm{~mL} \mathrm{~min}^{-1}$. The oven temperature was initially kept at $80^{\circ} \mathrm{C}$ for $2 \mathrm{~min}$ and then programmed to increasing gradients of 
$10^{\circ} \mathrm{C} \mathrm{min}^{-1}$, from $80^{\circ} \mathrm{C}$ to $200^{\circ} \mathrm{C}$, and $4^{\circ} \mathrm{C} \mathrm{min}^{-1}$ between $200^{\circ} \mathrm{C}$ and $270^{\circ} \mathrm{C}$. The mass spectra (GC$\mathrm{MS}$ ) were obtained with the ionization voltage at $70 \mathrm{eV}$ and registered in a range $\mathrm{m} / \mathrm{z}$ 30-500 Da.

Each peak in the chromatogram corresponded to a compound, each compound was identified based on the retention index (considering a homologous series of $\mathrm{C}_{\mathrm{s}}-\mathrm{C}_{2 \mathrm{n}} \mathrm{n}$-alkanes), the Kovats Index (KI) by comparing the fragmentation pattern of each compound with the mass spectra deposited in the virtual database and those reported in the literature (Adams 2012).

Gas chromatography (GC) equipped with flame ionization detector (FID)

Quantitative analysis was performed on a GC equipped with FID using a silica nonpolar capillary column Restek Rtx-5ms (30 m x 0.25 mm i.d. x $0.25 \mu \mathrm{m}$ film thickness) under the same conditions described for GC-MS. The relative amounts of the fatty acids in the algae, expressed in percentage, were calculated based on the peak areas in the chromatograms recorded without using correction factors, considering the total area of the peaks at $100 \%$.

\section{DPPH RADICAL SCAVENGING CAPACITY}

The DPPH radical scavenging activity of fatty acids from marine red algae $P$. capillacea and $O$. obtusiloba was determined according to the method of Blois (1958). The sample consisted of mixing an aliquot of $0.5 \mathrm{~mL}$ fatty acids at different concentrations (from 12.5 to $100 \mu \mathrm{g} \mathrm{mL}^{-1}$ ) and $2.5 \mathrm{~mL}$ DPPH methanol solution $75 \mu \mathrm{M}$. In the blank sample, the DPPH methanol solution was replaced with $\mathrm{MeOH}$, and in the control, were used only $3 \mathrm{~mL}$ DPPH methanol solution. The tubes (sample, blank sample and control) were incubated in the dark for $30 \mathrm{~min}$ at room temperature, and absorbance read at $517 \mathrm{~nm}$ on a microplate reader (Biochrom Asys UVM 340). Ascorbic acid was used as positive control. The DPPH radical scavenging percentage was calculated according to the following expression:

DPPH radical scavenging capacity $(\%)=\left[1-\frac{\left(A b s_{\text {sample }}-A b s_{\text {blank }}\right)}{A b s_{\text {control }}}\right] \times 100 \%$

\section{FERROUS IONS CHELATING ACTIVITY (FIC)}

Determination of FIC of fatty acids from marine red algae $P$. capillacea and $O$. obtusiloba was made according to the method of Wang et al. (2009). The sample consisted of $1 \mathrm{~mL}$ fatty acids at different concentrations (from 12.5 to $100 \mu \mathrm{g} \mathrm{mL}^{-1}$ ), $1.35 \mathrm{~mL}$ distilled water, $50 \mu \mathrm{L} 2 \mathrm{mM}$ ferrous chloride and $100 \mu \mathrm{L} 5 \mathrm{mM}$ ferrozine. In the blank sample, 100 $\mu \mathrm{L}$ distilled water replaced ferrozine, while in the control, $1 \mathrm{~mL}$ water was used instead of fatty acids. Sample, blank sample and control were incubated for $10 \mathrm{~min}$ at room temperature, and the absorbance read at $562 \mathrm{~nm}$ on a microplate reader (Biochrom Asys UVM 340). Ethylenediaminetetraacetic acid (EDTA) was used as a positive control. FIC percentage was calculated according to the following expression:

Ferrous ion chelating ability $(\%)=\frac{\left[A b s_{\text {control }}-\left(A b s_{\text {sample }}-A b s_{\text {blank }}\right)\right]}{A b s_{\text {control }}} \times 100 \%$

\section{FERRIC REDUCING ANTIOXIDANT POWER (FRAP)}

Determination of FRAP of fatty acids from marine red algae $P$. capillacea and O. obtusiloba was made according to Ganesan et al. (2008). To $1 \mathrm{~mL}$ fatty acids at different concentrations (from 12.5 to 100 $\mu \mathrm{g} \mathrm{ml}^{-1}$ ) were added $2.5 \mathrm{~mL} 0.2 \mathrm{M}$ phosphate buffer (pH 6.6) and $2.5 \mathrm{~mL} \mathrm{1 \%} \mathrm{potassium} \mathrm{ferricyanide.}$ This mixture was incubated for $20 \mathrm{~min}$ at $50^{\circ} \mathrm{C}$, cooled in ice water and then added with $2.5 \mathrm{~mL}$ $10 \%$ trichloroacetic acid. After stirring, $2.5 \mathrm{~mL}$ were taken and mixed with $2.5 \mathrm{~mL}$ distilled water and $0.5 \mathrm{~mL} 0.1 \%$ ferric chloride. After $10 \mathrm{~min}$ 
incubation at room temperature, the absorbance was read at $700 \mathrm{~nm}$ on a microplate reader (Biochrom Asys UVM 340). As a positive control, we used butylhydroxyanisole (BHA). Increases in absorbance indicated increases of FRAP, that is, the higher the absorbance, the greater the FRAP.

\section{$\beta$-CAROTENE BLEACHING (BCB)}

Determination of BCB of fatty acids from marine red algae $P$. capillacea and $O$. obtusiloba was performed by the method of Chew et al. (2008), with minor modifications. To $400 \mathrm{mg}$ Tween 40 emulsifier were added $2.5 \mathrm{mg} \beta$-carotene and 40 $\mathrm{mg}$ linoleic acid, both solubilized in chloroform. Then, the chloroform was evaporated in a rotary evaporator, and $100 \mathrm{~mL}$ ultrapure water saturated in $\mathrm{O}_{2}$ was added. The mixture was vigorously stirred to form an emulsion, from which were taken $3 \mathrm{~mL}$, added with $1 \mathrm{~mL}$ fatty acids at different concentrations (from 12.5 to $100 \mu \mathrm{g} \mathrm{mL}^{-1}$ ) and then initial absorbance was read at $470 \mathrm{~nm}$. Tubes were incubated at $50^{\circ} \mathrm{C}$ for 3 hours, after which, the absorbance was read again at the same wavelength. The two readings performed in microplate reader (Biochrom ASYS UVM 340). The butylhydroxyanisole (BHA) was used as positive control. The antioxidant activity was calculated according to following equation. The two readings were performed in a microplate reader (Biochrom Asys UVM 340).

$$
\text { Antioxidant activity }(\%)=\left(\frac{A b s_{3 h}}{A b s_{\text {initial }}}\right) \times 100 \%
$$

\section{STATISTICAL ANALYSIS}

All data were presented as mean \pm standard deviation. The results were subjected to one-way ANOVA, followed by Tukey's test, whenever the null hypothesis is rejected, at $5 \%$ significance level $(p<0.05)$.

\section{RESULTS AND DISCUSSION}

CHEMICAL COMPOSITION OF FATTY ACIDS OF THE HEXANE EXTRACT OF MARINE RED ALGAE Pterocladiella capillacea (S. G. GMELIN) SANTELICES \& HOMMERSAND 1997 AND Osmundaria obtusiloba (C. AGARDH) R. E. NORRIS 1991

Lipids represent a large group of natural compounds including fats, waxes, sterols, fat-soluble vitamins (A, D, E, and K), mono- and diglycerides, phospholipids, carotenoids and others. They play important biological functions, such as energy storage, structural components of cell membranes and signaling molecules. Although humans and other mammals have several metabolic pathways both to synthesize and to catabolize them, some essential lipids can only be obtained through diet (Francavilla et al. 2013).

Fatty acid composition of Hex extracts from red marine algae $P$. capillacea and $O$. obtusiloba were determined by GC-MS (Figure 1).

The identified fatty acids were classified into saturated fatty acids (myristic acid, palmitic acid and stearic acid), monounsaturated fatty acids (palmitoleic acid, oleic acid and elaidic acid) and polyunsaturated fatty acids (linoleic acid, arachidonic acid and eicosapentaenoic acid). This is the first report on the fatty acid composition of marine red algae $P$. capillacea and $O$. obtusiloba.

Nine fatty acids were identified in both species, corresponding to $100 \%$ of the chemical composition of Hex extract of each alga. In the marine red alga $P$. capillacea, the main constituent was palmitic acid $(88.8 \%)$, followed by oleic (3.1\%), arachidonic $(2.0 \%)$ and eicosapentaenoic (1.9\%) acids. In $O$. obtusiloba, the major constituents were palmitic acid (55.6\%), eicosapentaenoic acid (9.1\%), oleic acid (8.9\%) and arachidonic acid (8.5\%) (Table I).

Fatty acid profiles of Hex extracts from marine red algae $P$. capillacea and $O$. obtusiloba were similar, with a difference: the monounsaturated 
a)

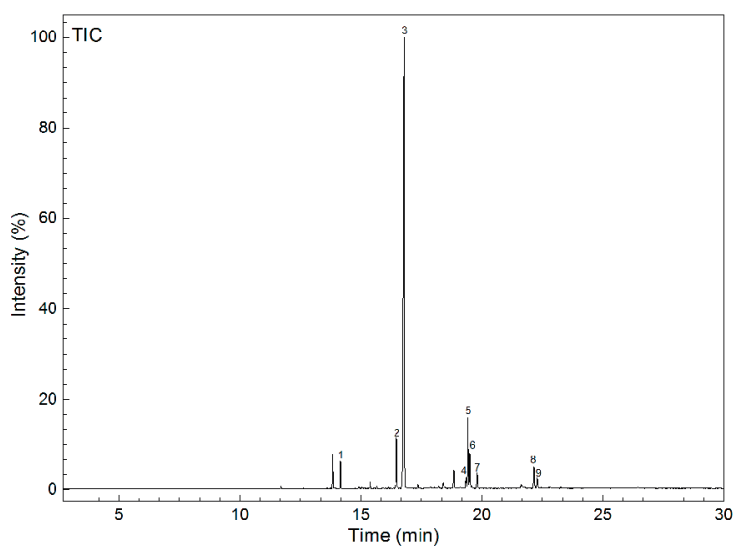

b)

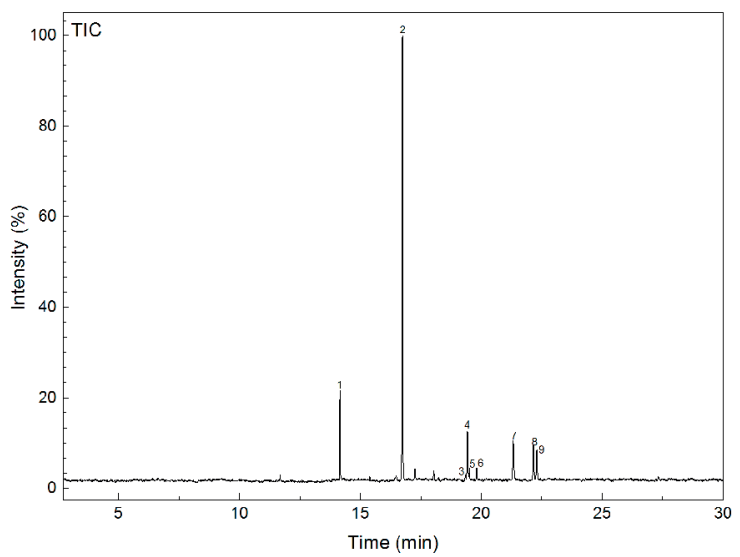

Figure 1 - Chromatograms of fatty acids from marine red algae Pterocladiellacapillacea (a) and Osmundariaobtusiloba (b) obtained by gas chromatography mass spectrometry (GC-MS).

fatty acids, palmitoleic acid, present in $P$. capillacea and nonadecenoic acid, in O. obtusiloba.

The fatty acid profile of $P$. capillacea showed a high percentage of saturated fatty acids $(90.6 \%)$ due to the content of palmitic acid (C16:0), which, alone, contributed with $88.8 \%$ of the total. Oleic acid (C18:1 cis) was the major constituent among monounsaturated fatty acids and arachidonic (20:4) and eicosapentaenoic (C20:5) acids among polyunsaturated fatty acids.

In $O$. obtusiloba, the percentage of saturated fatty acids was $63.4 \%$, due to the contents of palmitic (C16:0) and myristic (C14:0) acids, which together amounted to $61.6 \%$ of the total. Oleic acid (C18:1 cis) and nonadecenoico acid (C19:1 n9) were the major constituents of monounsaturated
TABLE I

Chemical composition of fatty acids of the hexane extract from marine red algae Pterocladiella capillacea $(P c)$ and Osmundaria obtusiloba $(\mathrm{Oo})$.

\begin{tabular}{|c|c|c|c|}
\hline \multirow{2}{*}{$\begin{array}{l}\text { Retention } \\
\text { time (min) }\end{array}$} & \multirow{2}{*}{ Fatty acids } & \multicolumn{2}{|c|}{$\begin{array}{l}\text { Relative } \\
\text { content }\end{array}$} \\
\hline & & $P c$ & Oo \\
\hline 14.15 & *Myristic acid (C14:0) & 0.9 & 6.0 \\
\hline 16.47 & $* *$ Palmitoleic acid (C16:1) & 1.0 & nd \\
\hline 16.78 & *Palmitic acid (C16:0) & 88.8 & 55.6 \\
\hline 19.33 & $* * *$ Linoleic acid (C18:2) & 0.4 & 0.8 \\
\hline 19.42 & **Oleic acid (C18:1 cis) & 3.1 & 8.9 \\
\hline 19.51 & **Elaidic acid (C18:1 trans) & 1.0 & 2.5 \\
\hline 19.80 & *Stearic acid (C18:0) & 0.9 & 1.8 \\
\hline 21.32 & $\begin{array}{c}* * \text { Nonadecenoic acid } \\
(\mathrm{C} 19: 1 \mathrm{n} 9)\end{array}$ & nd & 6.8 \\
\hline 22.15 & $* * *$ Arachidonic acid (20:4) & 2.0 & 8.5 \\
\hline 22.28 & $\begin{array}{c}* * * \text { Eicosapentaenoic acid } \\
\text { (EPA) }(\mathrm{C} 20: 5)\end{array}$ & 1.9 & 9.1 \\
\hline & Total SFA & 90.6 & 63.4 \\
\hline & Total AGMI & 5.1 & 18.2 \\
\hline & Total AGPI & 4.3 & 18.4 \\
\hline
\end{tabular}

*Saturated fatty acids (SFA);

**Monounsaturated fatty acids (MUFA);

***Polyunsaturated fatty acids (PUFA); nd - non-detected.

fatty acids and arachidonic (20:4) and eicosapentaenoic (C20:5) acids were the majority among polyunsaturated fatty acids.

This is the first report of the fatty acid composition of marine red alga $P$. capillacea and O. obtusiloba. Other studies on fatty acids with an alga belonging to the same family of $P$. capillacea and O. obtusiloba, Rhodophyta Gracilaria gracilis, showed that it is rich in polyunsaturated fatty acids, especially arachidonic and eicosapentaenoic acids (Francavilla et al. 2013).

Fatty acids present in seaweed are important for human and animal health, and are precursors of eicosanoids and act as bioregulators of cellular processes (Khotimchenko 2005). Polyunsaturated fatty acids $\omega-3$, eicosapentaenoic (EPA) and 
docosahexaenoic (DHA) are recognized as cardioprotective, reducing the levels of triglycerides and cholesterol, with anti-inflammatory activity and anti-cancer effects (Francavilla et. 2013). Linoleic and arachidonic acids present in P. capillacea and $O$. obtusiloba have the above functions.

The main constituent and the most representative of two species of algae is the palmitic acid, a saturated fatty acid, found at high percentages in $P$. capillacea $(88.8 \%)$ and O. obtusiloba (55.6\%). Studies in the literature corroborate our findings, in which the palmitic acid is present at higher amounts in marine red algae Ceramium virgatum, Chondrus crispus, Corallina pilulifera, Gracilaria crassa, G. domingensis, G. gracilis, G. vermiculophylla, Grateloupia turuturu, Osmundea pinnatifida, Palmaria palmata, Porphyra dioica and Solieria chordalis (Baghel et al. 2014, Guaratini et al. 2012, Horincar et al. 2014, Kang et al. 2014, Kendel et al. 2015, Rodrigues et al. 2015, Santos et al. 2015, Shimid et al. 2014). Also, according to Harada et al. (2002) and Kendel et al. (2015), palmitic acid found in marine alga can be a promising antitumor agent, confirming its biotechnological potential.

\section{ANTIOXIDANT ACTIVITY OF FATTY ACIDS OF RED MARINE RED ALGAE PTEROCLADIELLA CAPILLACEA (S. G. GMELIN) SANTELICES \& HOMMERSAND 1997 AND OSMUNDARIA OBTUSILOBA (C. AGARDH) R. E. NORRIS 1991}

The antioxidant activity of fatty acids was evaluated by four methods: DPPH radical scavenging activity, ferrous ions chelating activity (FIC), ferric reducing antioxidant power (FRAP) and $\beta$-carotene bleaching (BCB).

The fatty acids exhibited DPPH radical scavenging activity at all concentrations tested (Figure 2). There was a small increase in activity (25.90\% to $29.97 \%$ ) with increased concentration, but without statistical significance $(p>0.05)$. The activity of the positive control (ascorbic acid) was

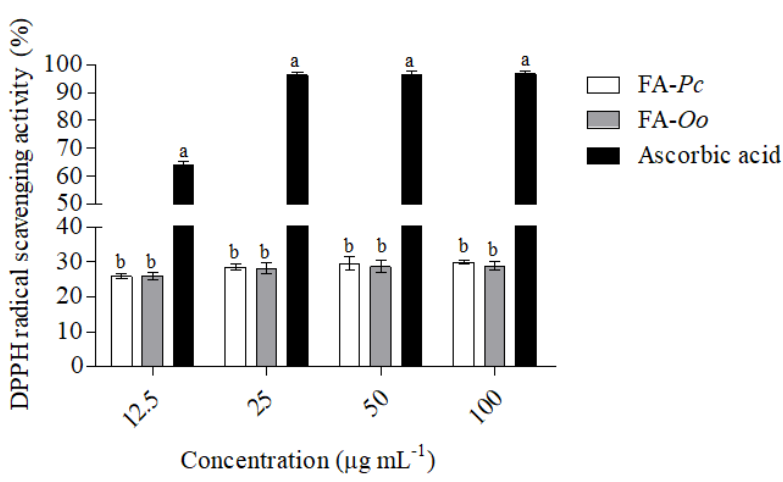

Figure 2 - DPPH radical scavenging activity of fatty acids (FA) present in the hexane extract from marine red algae Pterocladiella capillacea $(P c)$ and Osmundaria obtusiloba (Oo).

superior to that of samples tested, ranging from $64.23 \%$ to $96.82 \%$.

These results were expected since crude hexane extracts (Hex) from P. capillacea and O. obtusiloba showed moderate DPPH activity, $30.49 \%$ and $35.55 \%$, respectively (Alencar et al. 2016). Similar values were obtained by Patra et al. (2015), for hexadecanoic acid, the major constituent of the oil extracted from the marine green alga Enteromorpha linza, which presented a DPPH activity around $30 \%$ at a concentration of $100 \mu \mathrm{g} \mathrm{L}^{-1}$.

There was an indirect relationship between the concentration of fatty acids and FIC activity (Figure 3), that is, as the first increases, the second decreases. At all concentrations tested, chelating activity of fatty acids from $P$. capillacea was higher than that of O. obtusiloba. At the concentration of $12.5 \mu \mathrm{g} \mathrm{mL}^{-1}$, for example, they showed activities of $31.18 \%$ and $17.17 \%$, respectively.

The ferric reducing antioxidant power (FRAP) of fatty acids present in the Hex extract from marine red algae $P$. capillacea and $O$. obtusiloba was low (Figure 4). Unlike the observed for FIC, it was not possible to detect a dose dependent relationship. No concentration showed a statistically significant difference regarding the activity of fatty acids of the algae studied, except for the concentration of 50 


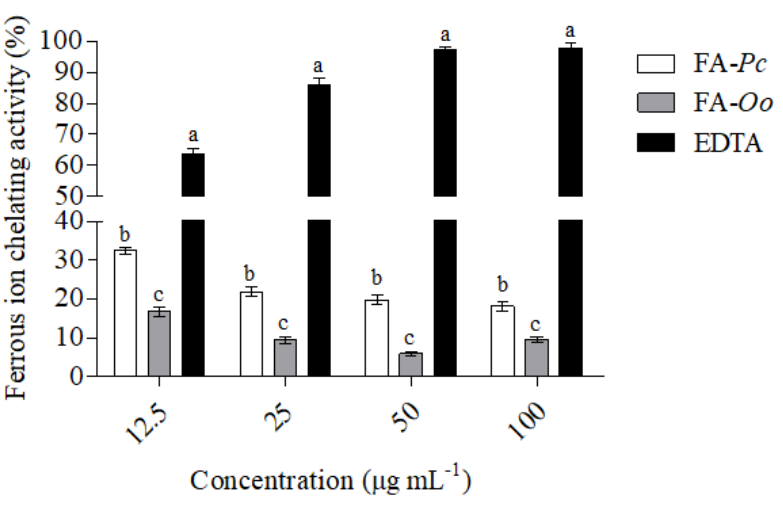

Figure 3 - Ferrous ions chelating activity (FIC) of fatty acids (FA) present in the hexane extract from marine red algae Pterocladiella capillacea $(P c)$ and Osmundaria obtusiloba $(\mathrm{Oo})$.

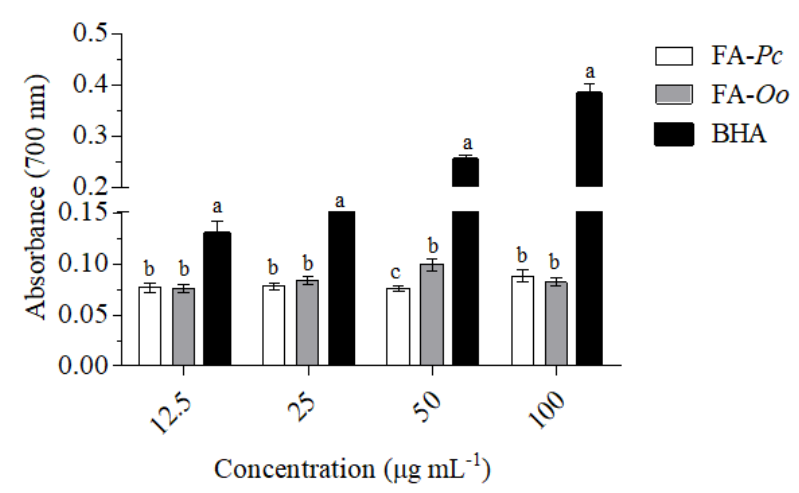

Figure 4 - Ferric reducing antioxidant power (FRAP) of fatty acids (FA) present in the hexane extract from marine red algae Pterocladiella capillacea $(P c)$ and Osmundaria obtusiloba $(\mathrm{Oo})$.

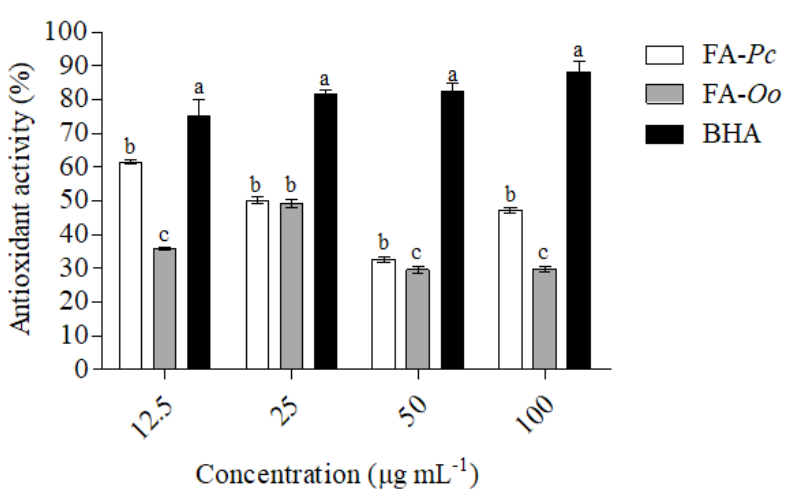

Figure 5 - $\beta$-carotene bleaching $(\mathrm{BCB})$ of fatty acids (FA) present in the hexane extract from marine red algae Pterocladiella capillacea $(P c)$ and Osmundaria obtusiloba $(\mathrm{Oo})$. $\mu \mathrm{g} \mathrm{L} \mathrm{L}^{-1}$. The activity of the positive control (BHA) was superior to that of samples tested, and the absorbance varied between 0.124 and 0.371 .

Figure 5 illustrates the antioxidant activity of $\beta$-carotene bleaching test observed in fatty acids present in Hex extracts from marine red algae $P$. capillacea and $O$. obtusiloba. It was observed the same behavior for the activity determined by FIC (inverse relationship between concentration and activity), where the highest concentration had the lowest antioxidant activity. For example, $P$. capillacea extract at $12.5 \mu \mathrm{g} \mathrm{mL}^{-1}$ showed $61.24 \%$ activity, while the extract from $O$. obtusiloba at 50 $\mu \mathrm{g} \mathrm{mL} \mathrm{m}^{-1}$ exhibited the highest activity $(49.13 \%)$. None of the samples showed activity superior to that of the positive control, BHT.

The antioxidant activities tested by the aforementioned methods are associated with the fatty acid content from $P$. capillacea, which has greater amount of saturated fatty acids $(90.6 \%)$ and lower of mono- and polyunsaturated fatty acids (9.4\%). In O. obtusiloba, the saturated fatty acids content is $63.4 \%$ and the mono- and polyunsaturated fatty acids content, $36.6 \%$. Possibly the mono- and polyunsaturated fatty acids are more susceptible to oxidation promoted by catalysts such as metal ions or hydroperoxide radicals due to the degree of unsaturation.

The antioxidant activity of fatty acids (saturated and unsaturated) is related to the composition of these acids found in marine algae. Henry et al. (2002) evaluated the antioxidant activity of saturated and unsaturated fatty acids and verified that saturated fatty acids, such as myristic, palmitic and lauric acids, showed the best antioxidant activity in the vegetable-origin products. These authors also claimed that the antioxidant activity is directly related to the size of the hydrocarbon chain in the structure of the fatty acid molecule.

According to Huang and Wang (2004), the antioxidant activity is also associated with the composition of fatty acids (saturated and 
unsaturated) present in algae. They showed that the antioxidant activity is related to the increased content of unsaturated fatty acids. Therefore, the unsaturated fatty acids seem to be the main components for contributing to the antioxidant activity of lipophilic extracts of marine alga. The antioxidant activity of fatty acids in marine alga is poorly addressed in the literature. The few studies on the subject discuss the activity given by the DPPH scavenging capacity and the $\beta$-carotene bleaching.

\section{CONCLUSIONS}

This is the first report on the fatty acid composition (qualitatively analyzed as fatty acids in the form of methyl esters by GC-MS and quantitatively by GC-FID) from the marine red algae Pterocladiella capillacea (S. G. Gmelin) Santelices \& Hommersand 1997 and Osmundaria obtusiloba (C. Agardh) R. E. Norris 1991, as well as on the antioxidant activity of these compounds.

The fatty acid profile of $P$. capillacea showed a high percentage of saturated fatty acids mainly because of the content of palmitic acid (C16:0). The major constituent among monounsaturated fatty acids was oleic acid (C18:1 cis), and among polyunsaturated fatty acids, arachidonic (20:4) and eicosapentaenoic (C20:5) acids.

In O. obtusiloba, the percentage of saturated fatty acids was also the highest, due to the contents of palmitic (C16:0) and myristic (C14:0) acids. Oleic acid (C18:1 cis) and nonadecenoic acid (C19:1 n9) were the major constituents of monounsaturated fatty acids and arachidonic (20:4) and eicosapentaenoic (C20:5) acids were the majority among polyunsaturated fatty acids.

Using the method of $\beta$-carotene bleaching (BCB), fatty acids showed antioxidant activity above $50 \%$ at the lowest concentrations, suggesting that these algae can be sources of beneficial supplements for animal and human health. In addition, fatty acids from marine algae can be used in the food industry to enrich food and provide a protective effect against lipid oxidation, thus extending food shelf life.

\section{ACKNOWLEDGMENTS}

The authors would like to express their thanks for the grants and financial support received from the Conselho Nacional de Desenvolvimento Científico e Tecnológico (CNPq), Fundação Cearense de Apoio ao Desenvolvimento Científico e Tecnológico (FUNCAP) and Coordenação de Aperfeiçoamento de Pessoal de Nível Superior (CAPES) of the Brazilian Government. A.H. Sampaio is the senior investigator of CNPq (Brazil).

\section{REFERENCES}

ADAMS RP. 2012. Identification of essential oil components by gas chromatography/mass spectroscopy, $4^{\text {th }}$ ed., Carol Stream, Illinois: Allured Publishing Corporation.

ALENCAR DB ET AL. 2014. Antioxidant potential and cytotoxic activity of two red seaweed species, Amansia multifida and Meristiella echinocarpa, from the coast of Northeastern Brazil. An Acad Bras Cienc 86: 251-263.

ALENCAR DB ET AL. 2016. Bioactive extracts of red seaweeds Pterocladiella capillacea and Osmundaria obtusiloba (Floridophyceae: Rhodophyta) with antioxidant and bacterial agglutination potential. Asian Pac J Trop Med 9: 372-379.

BAGHEL RS, KUMARI P, REDDY CRK AND JHA B. 2014. Growth, pigments, and biochemical composition of marine red alga Gracilaria crassa. J Appl Phycol 26: 2143-2150.

BLOIS MS. 1958. Antioxidant determinations by the use of a stable free radical. Nature 181: 1199-1200.

BOISVERT C, BEAULIEU L, BONNET C AND PELLETIER E. 2015. Assessment of the antioxidant and antibacterial activities of three species of edible seaweeds. J Biochem 39: 377-387.

CHEW YL, LIM YY, OMAR M AND KHOO KS. 2008. Antioxidant activity of three edible seaweeds from two areas in South East Asia. LWT-Food Sci Technol 41: 10671072.

DOLATABADI JEN AND KASHANIAN S. 2010. A review on DNA interaction with synthetic phenolic food additives. Food Res Int 43: 1223-1230.

FERNANDES DRP, OLIVEIRA VP AND VALENTIN YY. 2014. Seaweed biotechnology in Brazil: six decades of 
studies on natural products and their antibiotic and other biological activities. J Appl Phycol 26: 1923-1937.

FRANCAVILLA M, FRANCHI M, MONTELEONE M AND CAROPPO C. 2013. The red seaweed Gracilaria gracilis as a multi products source. Mar Drugs 11: 3754-3776.

GANESAN P, KUMAR CS AND BHASKAR N. 2008. Antioxidant properties of methanol extract and its solvent fractions obtained from selected Indian red seaweeds. Bioresource Technol 99: 2717-2723.

GUARATINI T, LOPES NP, MARINHO-SORIANO E, COLEPICOLO O AND PINTO E. 2012. Antioxidant activity and chemical composition of the non polar fraction of Gracilaria domingensis (Kützing) Sonder ex Dickie and Gracilaria birdiae (Plastino \& Oliveira). Rev Bras Farmacogn 22: 724-729.

HAFTING JT, CRAIGIER JS, STENGEL DB, LOUREIRO RR, BUSCHMANN AH, YARISH C, EDWARDS MD AND CRITCHLEY AT. 2015. Prospects and challenges for industrial production of seaweed bioactives. J Phycol 51: 821-837.

HARADA H, YAMASHITA U, KURIHARA H, FUKUSHI E, KAWABATA J AND KAMEI Y. 2002. Antitumor activity of palmitic acid found as a selective cytotoxic substance in a marine red alga. Anticancer Res 22: 2587-2590.

HENRY GH, MOMIN RA, NAIR MG AND DEWITT DL. 2002. Antioxidant and ciclooxygenase activities of fatty acids found in food. J Agr Food Chem 50: 2231-2234.

HOLDT SL AND KRAAN S. 2011. Bioactive compounds in seaweed: Functional food applications and legislation. J Appl Phycol 23: 543-597.

HORINCAR VB, PARFENE G, TYAGI AK, GOTTARDI D, DINICA R, GUERZONI ME AND BAHRIM G. 2014. Extraction and characterization of volatile compounds and fatty acids from red and green macroalgae from the Romanian Black Sea in order to obtain valuable bioadditives and biopreservatives. J Appl Phycol 26: 551559.

HUANG HL AND WANG BG. 2004. Antioxidant capacity and lipophilic content of seaweeds collected from the Qingdao coastline. J Agr Food Chem 52: 4993-4997.

JOSEPH JD AND ACKMAN RG. 1992. Capillary column gas-chromatographic method for analysis of encapsulated fish oils and fish oil ethyl-esters: Collaborative study. J AOAC Int 75: 488-506.

KANG JY, BENLIRO IMP, LEE IJ, CHOI JY, JOO J, CHOI YS, HWANG DS AND HONG YK. 2014 Viability, fatty acid composition, and structure of the coralline alga Corallina pilulifera. Bot Sci 92: 103-109.

KENDEL M, WIELGOSZ-COLLIN G, BERTRAND S, ROUSSAKIS C, BOURGOUGNON N AND BEDOUX G. 2015. Lipid composition, fatty acids and sterols in the seaweeds Ulva armoricana, and Solieria chordalis from Brittany (France): An analysis from nutritional, chemotaxonomic, and antiproliferative activity perspectives. Mar Drugs 13: 5606-2628.

KHOTIMCHENKO SV. 2005. Lipids from the marine alga Gracilaria verrucosa. Chem Nat Compd 41: 285-288.

LORDAN S, ROSS RP AND STANTON C. 2011. Marine bioactives as functional food ingredients: Potential to reduce the incidence of chronic diseases. Mar Drugs 9: 1056-1100.

NGO DH, VO TS, NGO DN, WIJESEKARA I AND KIM SK. 2012. Biological activities and potential health benefits of bioactive peptides derived from marine organisms. Int $\mathrm{J}$ Biol Macromol 51: 378-383.

NGO DH, WIJESEKARA I, VO TS, TA QV AND KIM SK. 2011. Marine food-derived functional ingredients as potential antioxidants in food industry: An overview. Food Res Int 44: 523-529.

O'SULLIVAN AM, O'CALLAGHAN YC, O'GRADY MN, QUEGUINEUR B, HANNIFFY D, TROY DJ, KERRY JP AND O'BRIEN NM. 2011. In vitro and cellular antioxidant activities of seaweed extracts prepared from five brown seaweeds harvested in spring from the west coast of Ireland. Food Chem 126: 1064-1070.

PATRA JK, KIM SH AND BAEK KH. 2015. Antioxidant and free radical-scavenging potential of essential oil from Enteromorpha linza L. prepared by microwave-assisted hydrodistillation. J Food Biochem 39: 80-90.

PLOUGUERNÉ E, GAMA BAP, PEREIRA RC AND BARRETO-BERGTER E. 2014. Glycolipids from seaweeds and their potential biotechnological applications. Front Cell Infect Microbiol 4: 1-5.

RODRIGUES D, FREITAS AC, PEREIRA L, ROCHASANTOS TAP, VASCONCELOS MW, RORIZ M, RODRÍGUEZ-ALCALÁ LM, GOMES AMP AND DUARTE AC. 2015. Chemical composition of red, brown and green macroalgae from Buarcos bay in Central West coast of Portugal. Food Chem 183: 197-207.

SANTOS SAO, VILELA C, FREIRE CSR, ABREU MH, ROCHA SM AND SILVESTRE AJD. 2015. Chlorophyta and Rhodophyta macroalgae: A source of health promoting phytochemicals. Food Chem 183: 122-128.

SHIMID M, GUIHÉNEUF F AND STENGEL DB. 2014. Fatty acid contents and profiles of 16 macroalgae collected from the Irish Coast at two seasons. J Appl Phycol 26: 451-463.

SOUZA BWS, CERQUEIRA MA, MARTINS JT, QUINTAIS MAC, FERREIRA ACS, TEIXEIRA JA AND VICENTE AA. 2011. Antioxidant potential of two red seaweeds from the Brazilian coast. J Agr Food Chem 59: 5589-5594.

TIERNEY MS, SMYTH TJ, HAYES M, SOLER-VILA A, CROFT AK AND BRUNTON N. 2013. Influence of pressurised liquid extraction and solid-liquid extraction methods on the phenolic content and antioxidant activities of Irish macroalgae. Int J Food Sci Tech 48: 860-869. 
WANG T, JÓNSDÓTTIR R AND ÓLAFSDÓTTIR G. 2009.

Total phenolic compounds, radical scavenging and metal chelation of extracts from Icelandic seaweeds. Food Chem 116: $240-248$. 